\title{
The efficacy of ultrasonographic morphological index using Depriest score in ovarian cancer prediction
}

\author{
Hossam Hassan Aly Hassan El Sokkary*
}

Department of Obstetrics and Gynecology, El Shatby Maternity Hospital, Alexandria University, Alexandria, Egypt

Received: 03 October 2016

Revised: 05 October 2016

Accepted: 28 October 2016

\section{*Correspondence:}

Dr. Hossam Hassan Aly Hassan El Sokkary,

E-mail: hossamsokkary@ hotmail.com

Copyright: ( $)$ the author(s), publisher and licensee Medip Academy. This is an open-access article distributed under the terms of the Creative Commons Attribution Non-Commercial License, which permits unrestricted non-commercial use, distribution, and reproduction in any medium, provided the original work is properly cited.

\section{ABSTRACT}

Background: Ovarian cancer is the second most common cancer after cancer breast and the most lethal gynecologic malignancy in developed countries.The objective of this study was to evaluate the efficacy of ultrasonographic morphological index using Depriest score et al in identifying ovarian cancer and to calculate its specificity, sensitivity, positive predictive value and negative predictive value in ovarian cancer prediction.

Methods: Preoperative estimation of morphological index by Depriest score using vaginal ultrasound examination for 130 cases with ovarian masses, followed by laparotomy, and histopathological examination of the masses. Correlation of the cases morphological index score was done for histopathological nature of masses whether it is benign or malignant. Calculation of the Depriest index score was done using 3 parameters which are tumor volume, cyst wall structure and thickness and Septal structure.

Results: A significant difference were found between mean Depriest score $(\mathrm{p}=0.001)$ of malignant cases (mean score $8.27 \pm 1.77$ ) and benign cases (mean score $4.38 \pm 1.61$ ) while the mean volume showed no significant difference $(\mathrm{p}=0.101$ ) between malignant (mean volume $3.24 \pm 0.69$ ) and benign cases (mean volume $3.00 \pm 0.91$ ). In relation to CA125 there was a significant difference $(\mathrm{p}=0.001)$ between malignant (mean CA125 86.34 \pm 73.87$)$ and benign cases (mean CA125 31.48 \pm 12.83 ).

Conclusions: Depriest et al morphological index is an effective and cost efficient method for malignant ovarian masses prediction and differentiation from benign masses.

Keywords: Depriest et al score, Ovarian ultrasongraphic morphological index, Ovarian cancer prediction

\section{INTRODUCTION}

Ovarian cancer is the second most common cancer after cancer breast and the most lethal gynecologic malignancy in developed countries. Epithelial ovarian cancer comprises $90 \%$ of malignant ovarian tumors in adult women. The majority of women with ovarian cancer are diagnosed with advanced stage disease. ${ }^{1}$ Identification of adnexal mass whether benign or malignant is of great importance before surgery. Functional or simple ovarian cysts (thin-walled cysts without internal structures) which are less than $5 \mathrm{~cm}$ maximum diameter usually resolve spontaneously without the need for surgical intervention within 2 to 3 menstrual cycles. ${ }^{2}$ Benign masses can be treated conservatively or with laparoscopy, avoiding unnecessary costs and morbidity. On the other hand if malignancy is suspected, referral to a gynaecological oncologist is needed for proper staging and debulking surgery. ${ }^{3}$ Using of cost effective method as tumor markers for differentiation between benign and malignant ovarian masses is of great help. CA125 is the first marker that have been used for epithelial ovarian cancer screening but it is not specific because elevated level may be associated with other benign diseases as fibroid, endometriosis, pelvic inflammatory disease, benign cyst and menstruation and other malignant diseases as cancer 
breast ,gastric cancer, leiomyosarcoma of gastrointestinal origin and non-Hodgkin lymphoma. ${ }^{4-7}$ Ultrasonographic examination of adnexal masses is a simple cost effective method with good access to the ovaries. It provide accurate assessment of size, can differentiate between cystic and solid lesions, monitor changes in appearance, and assess vascular supply and flow. Limitation of ultrasonographic examination of adnexal masses is dependency on operator and quality of machine used. This is the cause of using many models with different ultrasound marker for diagnosing ovarian cancer. ${ }^{8,9}$ These models have a number of quantitative indexes relating ovarian tumor morphology to risk of malignancy. ${ }^{10}$ The tumor-morphology index reported by Ueland et al is illustrated in Figure 1. Numeric scores (1-5) are given in the categories of tumor volume and tumor morphology, with a combined total score ranging from 0 to $10 .{ }^{11}$ Other morphological indexes include the index of Depriest et al which is the first one that evaluate the morphological pattern of ovarian masses and give a score that correlate with malignancy Depriest et al developed a scoring system based on volume, cyst wall structure, and septal structure of adenexal mass assessed by sonography. A point scale (0 to 4 ) was developed within each category, with the total points per evaluation varying from 0 to 12 . Table 1 demonstrates how to calculate the score (Table 1). ${ }^{12} \mathrm{We}$ noticed that the septum structure which Depriest et al. had included into their scoring system was omitted from the MI system by Ueland et al, that is why we need to evaluate Depriest et al morphological index. The aim of the study was to evaluate the efficacy of ultrasonographic morphological index using Depriest score et al in identifying ovarian cancer and to calculate its specificity, sensitivity, positive predictive value and negative predictive value in ovarian cancer prediction.

Table 1: How to calculate ovarian mass morphological index using original Depriest et al score. (Morphology index for ovarian tumors).

\begin{tabular}{|c|c|c|c|c|c|}
\hline & 0 & 1 & 2 & 3 & 4 \\
\hline Volume & $<10 \mathrm{~cm}^{3}$ & $10-50 \mathrm{~cm}^{3}$ & $>50-200 \mathrm{~cm}^{3}$ & $>200-500 \mathrm{~cm}^{3}$ & $>500 \mathrm{~cm}^{3}$ \\
\hline $\begin{array}{l}\text { Cyst wall } \\
\text { structure }\end{array}$ & $\begin{array}{l}\text { Smooth } \\
<3 \mathrm{~mm} \text { thickness }\end{array}$ & $\begin{array}{l}\text { Smooth } \\
>3 \mathrm{~mm} \text { thickness }\end{array}$ & $\begin{array}{l}\text { Papillary projections } \\
<3 \mathrm{~mm}\end{array}$ & $\begin{array}{l}\text { Papillary } \\
\text { projection } \geq 3 \mathrm{~mm}\end{array}$ & $\begin{array}{l}\text { Predominantly } \\
\text { solid }\end{array}$ \\
\hline Septa structure & No septa & $\begin{array}{l}\text { Thin septa }<3 \\
\mathrm{~mm}\end{array}$ & $\begin{array}{l}\text { Thick septa } 3 \mathrm{~mm}- \\
10 \mathrm{~mm}\end{array}$ & $\begin{array}{l}\text { Solid area } \\
\geq 10 \mathrm{~mm}\end{array}$ & $\begin{array}{l}\text { Predominantly } \\
\text { solid }\end{array}$ \\
\hline
\end{tabular}

Depriest et al. Gynecol Oncol 1993;51:7-11.

\section{METHODS}

Observational prospective study was done for 130 cases with ovarian masses in Shat by maternity university hospital from January 2010 to June 2015.

Following approval by our institutional ethics committee, an observational prospective study was done for 130 cases with ovarian masses. Preoperative estimation of morphological index of ovarian masses by Depriest score using vaginal ultrasound examination performed with a 5-7.5 $\mathrm{mHz}$ vaginal probe, followed by laparotomy, and histopathological examination of the masses. Preoperative estimation of serum CA125, and abdominopelvic CT scan to suspect malignancy in all cases were done. Cases suspected to be malignant by risk of malignancy index type 2 (score more than 200) underwent complete surgical staging which included the following total abdominal hysterectomy with salpingooopherectomy, peritoneal wash for cytology, infracolic omentectomy, multiple peritoneal biopsies, plus biopsy from suspicious intrabdominal lesion and pelvic lymphadenectomy (external iliac and obturator groups after written informed consent. While suspected benign cases underwent laparotomy in which conservative or surgical staging was done according to the operative finding.
Correlation of the cases morphological index score was done for histopathological nature of masses whether it is benign or malignant. Calculation of the Depriest index score was done using 3 parameters which are tumor volume, cyst wall structure and thickness and septal structure. Ovarian volume is calculated using the prolate ellipsoid formula (length $\times$ width $\times$ height $\times 0.523$ ). A point scale (0 to 4 ) was developed within each category, with the total points per evaluation varying from 0 to 12.the following table demonstrates how to calculate the score (Table 1).

\section{Statistical analysis}

The Data was collected and entered into the personal computer. Statistical analysis was done using Statistical Package for Social Sciences (SPSS/version 20) software.

Arthematic mean, standard deviation, to compare between two groups, t-test was used, while for more than two groups ANOVA test was used. To find the association between two variables, spearman correlation coefficient test was used. ROC curve was used to determine the sensitivity, specificity, PPV, NPV and accuracy of marker. The level of significant was 0.05 . 


\section{Justification of sample size}

Assuming area under ROC to be 0.80 , an alpha of 0.05 and power of study $90.0 \%$. A minimum sample size required was calculated to be 130 cases with ovarian masses.

\section{RESULTS}

Table 2 summarizes the demographic and pathological data of the studied 130 cases with ovarian mass. Histopathological examination of the cases revealed 88 malignant cases distributed as follow: 45 cases $(67.7 \%)$ were Papillary Serous cystadenocarcinoma, 7 cases (5.4\%) were borderline Papillary Serous cystadenocarcinoma, 4 cases $(3.1 \%)$ were Papillary Serous adenocarcinoma, 15 cases (11.5\%) were Endometroid adenocarcinoma, 12 cases (9.2\%) were Pseudomucinous adenocarcinoma, 3 cases $(2.3 \%)$ were Border line Pseudomucinous adenocarcinoma and 2 cases $(1.5 \%)$ were clear cell adenocarcinoma. Benign cases were 42 distributed as follow: 24 cases (18.5\%) were Pseudomucinous cystadenoma, 16 cases $(12.5 \%)$ were seous cystadenoma and 2 cases (1.5\%) were endometriotic cyst.

Table 2: Demographic and pathological data of the studied ovarian masses patients.

\begin{tabular}{|lll|}
\hline \multicolumn{2}{l}{ Number } & Percent \\
\hline Age & 11 & 8.5 \\
\hline$\leq 40$ & 77 & 59.2 \\
$40-50$ & 42 & 32.3 \\
$\geq 50$ & $37-60$ & \\
\hline Range & 47.3 & \\
$\begin{array}{l}\text { Mean } \\
\text { S.D. }\end{array}$ & 5.11 & \\
\hline Pathological diagnosis & & \\
\hline Malignant & 88 & 67.7 \\
\hline $\begin{array}{l}\text { Papillary serous } \\
\text { cystadenocarcinoma }\end{array}$ & 45 & 34.6 \\
\hline $\begin{array}{l}\text { Border line papillary serous } \\
\text { cystadenocarcinoma }\end{array}$ & 7 & 5.4 \\
\hline Papillary serous adenocarcinoma & 4 & 3.1 \\
\hline Endometroid adenocarcinoma & 15 & 11.5 \\
\hline Pseudomucinous adenocarcinoma & 12 & 9.2 \\
\hline $\begin{array}{l}\text { Border line Pseudomucinous } \\
\text { adenocarcinoma }\end{array}$ & 3 & 2.3 \\
\hline Clear cell adenocarcinoma & 2 & 1.5 \\
\hline Benign cases & 42 & 32.3 \\
\hline Pseudomucinous cystadenoma & 24 & 18.5 \\
\hline Serous cystadenoma & 16 & 12.3 \\
\hline Endometriotic cyst & 2 & 1.5 \\
\hline
\end{tabular}

Table 3 represents a comparison between benign and malignant ovarian masses in relation to age, Depriest score and its 3 parameters (ovarian masses volume, cyst wall structure and Septal structure) and CA125 serum level. As regards to age there was a significant difference $(\mathrm{p}=0.0021)$ between mean age of malignant cases (age

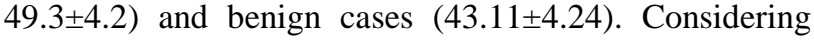
Depriest score and its 3 parameters, a significant difference were found between mean Depriest score $(\mathrm{p}=0.001)$ of malignant cases (mean score $8.27 \pm 1.77)$ and benign cases (mean score $4.38 \pm 1.61$ ), mean cyst wall structure scale point $(\mathrm{p}=0.001)$ between malignant (mean scale 2.72 \pm 0.96 ) and benign cases (mean scale $0.33 \pm 0.65)$ and mean Septal structure $(p=0.001)$ between malignant (mean scale 2.36 \pm 0.85 ) and benign cases (mean scale $2.36 \pm 0.85$ ), while the mean volume showed no significant difference $(\mathrm{p}=0.101)$ between malignant (mean volume 3.24 \pm 0.69 ) and benign cases (mean volume $3.00 \pm 0.91)$. In relation to CA125 there was a significant difference $(\mathrm{p}=0.001)$ between malignant (mean CA125 86.34 \pm 73.87 ) and benign cases (mean CA125 31.48 \pm 12.83$)$.

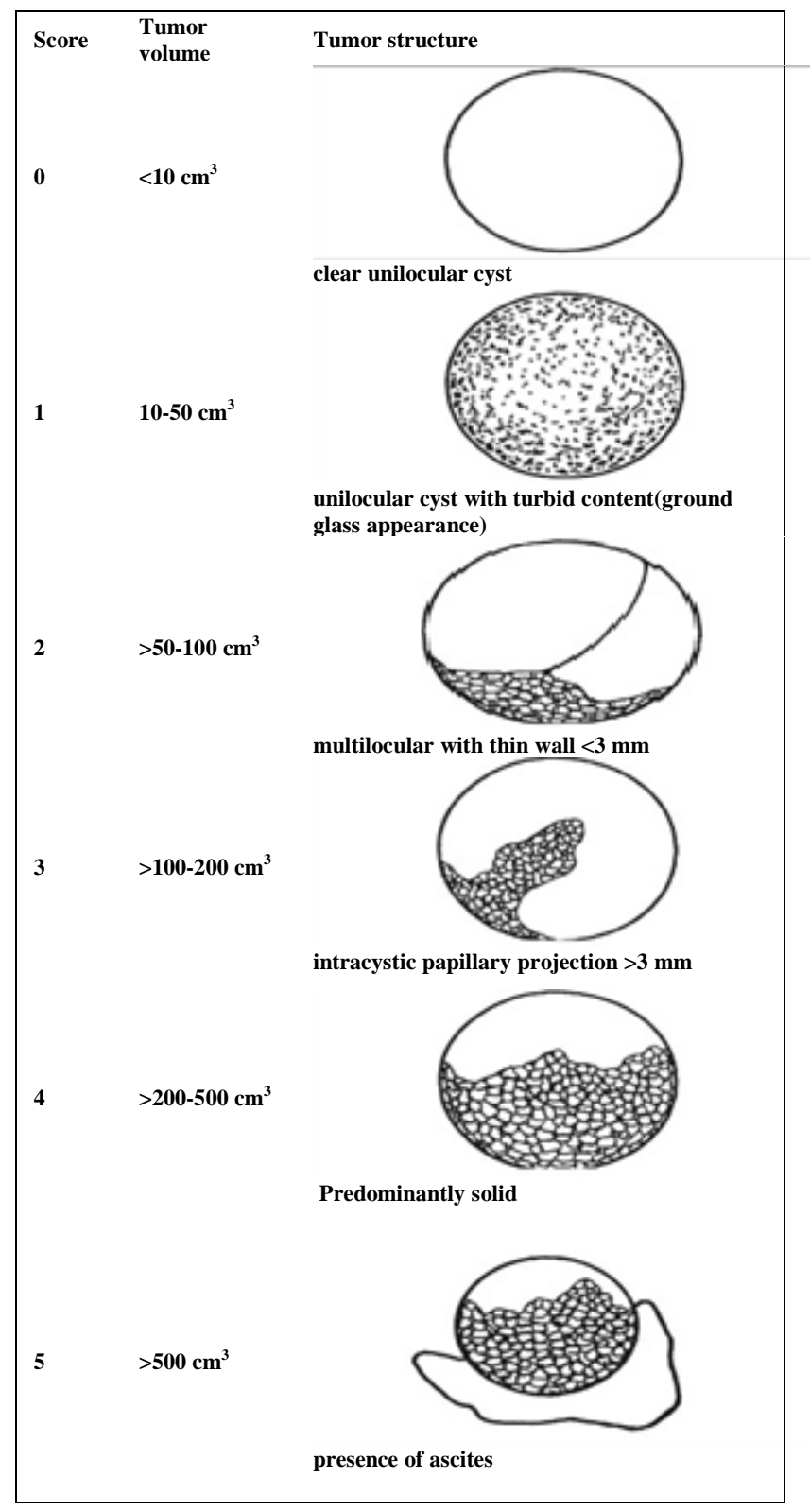

Figure 1: The university of Kentucky ovarian tumor morphology index. 
Figure 2 and Table 4 showed sensitivity, specificity, positive predictive value (PPV), negative predictive value (NPV) and accuracy of Depriest score in ovarian cancer prediction. Using cut off level of Depriest score less than 5 for benign cases diagnosis, the sensitivity, specificity, positive predictive value (PPV), negative predictive value (NPV) and accuracy were as follow: 100\%, 90\%, 100\%, $92 \%$ and $95 \%$ respectively. Using cut off level of Depriest score more than or equal to 5 to diagnose malignant cases which included border line and invasive ovarian malignancy types, the sensitivity, specificity, positive predictive value (PPV), negative predictive value (NPV) and accuracy were as follow: 100\%,46.2\%,100\%, $45 \%$ and $62 \%$ respectively while using Depriest score cut off level more than or equal 7 for malignant cases diagnosis, the sensitivity, specificity, positive predictive value (PPV), negative predictive value (NPV) and accuracy were as follow: $95 \%, 70 \%, 91 \%, 74 \%$ and $72 \%$ respectively.

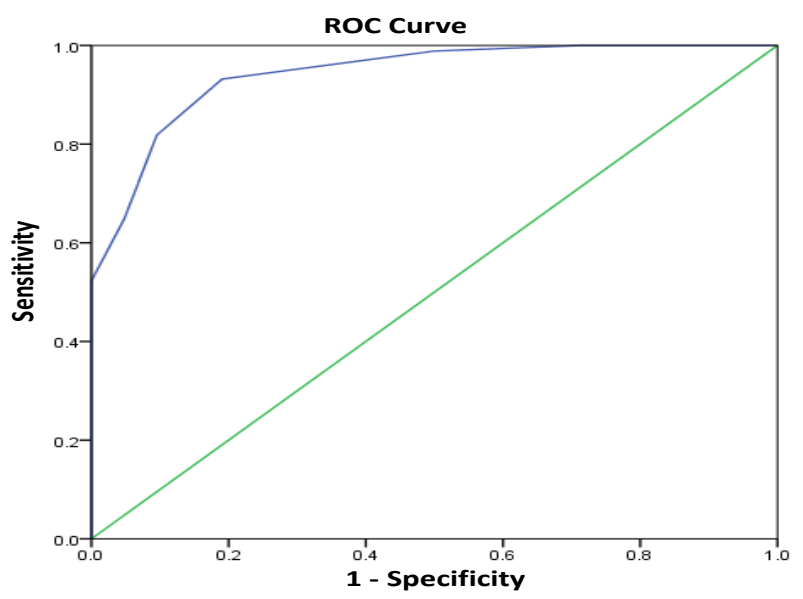

Figure 2: ROC curve shows sensitivity, specificity, PPV, NPV and accuracy of calculation of Depriest score in ovarian cancer prediction.

Table 3: Comparison between benign and malignant and other measured variables.

\begin{tabular}{|llll|}
\hline & Malignant & Benign & P \\
\hline Age & $49.3 \pm 4.2$ & $43.11 \pm 4.24$ & $0.0021^{*}$ \\
\hline volume & $3.24 \pm 0.69$ & $3.00 \pm 0.91$ & 0.101 \\
\hline Cyst wall structure & $2.72 \pm 0.96$ & $0.33 \pm 0.65$ & $0.001^{*}$ \\
\hline Septa structure & $2.36 \pm 0.85$ & $1.02 \pm 0.72$ & $0.001^{*}$ \\
\hline Depriest score & $8.27 \pm 1.77$ & $4.38 \pm 1.61$ & $0.001^{*}$ \\
\hline Ca125 & $86.34 \pm 73.87$ & $31.48 \pm 12.83$ & $0.001^{*}$ \\
\hline
\end{tabular}

Table 4: Sensitivity, specificity, PPV, NPV and accuracy of Depriest score in ovarian cancer prediction.

\begin{tabular}{|llllllll|}
\hline Area under the curve & Cut off value & Sensitivity & Specificity & PPV & NPV & Accuracy Diagnosis \\
\hline 0.942 & $<5$ & 100.0 & 90.0 & 100.0 & 92.0 & 95.0 & Benign cases \\
\hline & $\geq 5$ & 100.0 & 46.2 & 100.0 & 45.0 & 62.0 & Malignant cases \\
\hline & $\geq 7$ & 95.0 & 70.0 & 91.0 & 74.0 & 72.0 & Malignant cases \\
\hline
\end{tabular}

\section{DISCUSSION}

Ultrasonography (US) is considered to be the primary imaging modality used to identify and characterize adnexal masses. ${ }^{13}$ Many approaches have been used to identify ovarian masses whether it is benign or malignant as the University of Kentucky Ovarian Tumor Morphology Index reported by Ueland et al which omitted Septal structure and depend up on only 2 variables which are tumor volume and morphology. ${ }^{11}$ That's mean that tumor volume has the same importance as tumor morphology in indentifying ovarian malignancy which may weaken the specificity of the index. Depriest et al morphological index has 3 parameters not only 2 and use septal structure to calculate their scoring System. ${ }^{12}$ The International Ovarian Tumour Analysis (IOTA) group ultrasound rules for ovarian masses are a simple ultrasonographic findings that differentiate ovarian masses into benign, malignant. Ovarian masses that cannot be classified ( $-25 \%$ of ovarian masses) into either group are classified as "inconclusive" and further evaluation is needed. ${ }^{14}$ A logistic regression model type 1 and 2 has been developed in addition to simple rule by IOTA group, the model use personal history, symptomatology, Doppler examination in addition to gray-scale ultrasonograpy and it is more complicated than Depriest et al morphological index. The simple rules of IOTA group and the two logistic models were developed based on cases with adnexal masses selected to undergo surgery, because surgical outcome was needed to verify the correct histological diagnosis. That's mean that the logestic models and rules were not developed for women with adnexal cysts and tumors that were not referred for surgery. As a result of that, the logistic models and simple rules cannot be applied to conservatively treat adnexal masses. ${ }^{16}$

Depriest et al morphological index is very simple ,use only gray scale ultrasonography to examine its three parameters, does not use Doppler to estimate blood flow, 
personal history or symptomatology that lead to decrease variation between interobservers or examiners and depend up on 3 variables not only 2 as Ueland et al morphological index , that's why this article evaluate it.

Our result showed a significant difference between Depriest el al morphological index score of benign and malignant cases $(p=0.0021)$ which is consistent with Depriest PD, Shenson D, Fried A, Hunter JE et $\mathrm{al}^{12}$ and Depriest PD, Varner E, Powell J, Fried A, Puls L studies. ${ }^{17}$ One of the important finding in our result that's there was no significance difference in masses volume between benign and malignant cases $(p=0.101)$ on the other hand a significant difference was present in Septal structure point scale between benign and malignant cases $(\mathrm{p}=0.001)$.

That's why Septal structure of the masses is an important factor in differentiation between benign and ovarian cases in contradiction with Ueland et al study that omitted Septal structure and assign $50 \%$ of its score to ovarian volume which showed no significance difference between benign and malignant cases in article results. ${ }^{11}$

In relation to sensitivity, specificity, PPV and NPV, the present study showed a good sensitivity (100\%), specificity (90\%), PPV (100) and NPV (92\%) for benign cases when using morphological index score less than 5 . Using cut off level of Depriest score more than or equal 7 for malignant cases diagnosis, the sensitivity, specificity, positive predictive value (PPV), negative predictive value (NPV) and accuracy were as follow: 95\%, 70\%, 91\%, $74 \%$ and $72 \%$ respectively, while using cut level more than or equal to 5 lead to increase in sensivity to $100 \%$ but decrease specificity to 46.2. This finding is comparable to Depriest PD1, Varner E, Powell J, Fried A, Puls L study which use a cut level more than 5 and showed $89 \%$ sensitivity and $46 \%$ PPV. ${ }^{17}$ The difference is that the present study used cut level more than or equal to 7 in addition to more than or equal to 5 , to diagnose malignant ovarian cases and compared between them In relation to sensitivity, specificity, PPV and NPV.

From this study we can conclude that ulrasonographic examination of ovarian masses and calculation Depriest et al morphological index is an effective and cost efficient method in prediction of malignant ovarian masses, differentiation from benign masses and using Depriest et al morphological index cut level more than or equal to 7 was associated with $82 \%$ positive predictive value.

\section{CONCLUSION}

Depriest et al morphological index is an effective and cost efficient method for malignant ovarian masses prediction, differentiation from benign masses and using Depriest et al morphological index cut level more than or equal to 7 was associated with $82 \%$ positive predictive value.
Funding: No funding sources Conflict of interest: None declared

Ethical approval: The study was approved by the Institutional Ethics Committee

\section{REFERENCES}

1. Jemal A, Siegel R, Ward E. Many early ovarian cancers arise in the fallopian tube, and, more specifically, the distal fimbrial portion appears to be the most common site of origin. Cancer statistics, CA Cancer J Clin. 2006;56:106-30.

2. Levine D, Brown DL, Andreotti RF, Benacerraf B, Benson CB, Brewster WR, et al. Management of asymptomatic ovarian and other adnexal cysts imaged at US: society of radiologists in ultrasound consensus conference statement. Radiol. 2010;256:943-54.

3. Vernooij F, Heintz P, Witteveen E, van der Graaf Y. The outcomes of ovarian cancer treatment are better when provided by gynecologic oncologists and in specialized hospitals: a systematic review. Gynecol Oncol. 2007;105:801-12.

4. Meden H, Fattahi-Meibodi A. CA 125 in benign gynecological conditions. Int $\mathrm{J}$ Biol Markers. 1998;13:231-7.

5. Norum LF, Erikstein B, Nustad K. Elevated CA125 in breast cancer: a sign of advanced disease. Tumour Biol. 2001;22:223-8.

6. Burney IA, Siddiqui T, Siddiqui I. Serum CA 125 is of clinical value in the staging and follow-up of patients with non-Hodgkin's lymphoma: correlation with tumor parameters and disease activity. Cancer. 1999;85:755-6.

7. Yamamoto M, Baba H, Toh Y, Okamura T, Maehara Y. Peritoneal lavage CEA/CA125 is a prognostic factor for gastric cancer patients. J Cancer Res Clin Oncol. 2007;133(7):471-6.

8. Kaijser J, Sayahsneh A, Van Hoorde K. Presurgical diagnosis of adnexal tumors using mathematical models and scoring systems: a systematic review and meta-analysis. Hum Reprod Update. 2014;20:44962.

9. Timmerman D, Testa AC, Bourne T. Simple ultrasound-based rules for the diagnosis of ovarian cancer. Ultrasound Obstet Gynecol. 2008;31:681-90.

10. Ferrazzi E, Lissoni AA, Dordoni D. Differentiation of small adnexal masses based on morphological characteristics of trans-vaginal sonographic imaging. J Ultrasound Med. 2005;24:1467-73.

11. Ueland FR, Depriest PD, Pavlik EJ, Kryscio RJ, van Nagell JR. Preoperative differentiation of malignant from benign ovarian tumors: the efficacy of morphologic indexing and Doppler flow sonography. Gynecol Oncol. 2003;91:46-50.

12. Depriest PD, Shenson D, Fried A. A morphology index based on sonographic findings in ovarian cancer. Gynecol Oncol. 1993;51:7-11.

13. Liu J, Xu Y, Wang J. Ultrasonography, computed tomography and magnetic resonance imaging for 
diagnosis of ovarian carcinoma. Eur $\mathrm{J}$ Radiol. 2007;62:328-34.

14. Kaijser J, Bourne T, Valentin L. Improving strategies for diagnosing ovarian cancer: a summary of the International Ovarian Tumor Analysis (IOTA) studies. Ultrasound Obstet Gynecol. 2013;41:9-20.

15. Timmerman D, Testa AC, Bourne T, Ameye L, Jurkovic D, Van Holsbeke C, et al. Simple ultrasound-based rules for the diagnosis of ovarian cancer, Ultrasound in Obstetrics and Gynecology. 2008;31:681-90.

16. Timmerman D, Testa AC, Bourne T, Ferrazzi E, Ameye L, Konstantinovic ML, et al. Logistic regression model to distinguish between the benign and malignant adnexal mass before surgery: a multicenter study by the International Ovarian Tumor Analysis Group. J Clin Oncol. 2005;23:8794801.

17. Depriest PD, Varner E, Powell J, Fried A, Puls L, Higgins R, et al. The efficacy of a sonographic morphology index in identifying ovarian cancer: a multi-institutional investigation. Gynecol Oncol. 1994;55:174-8.

Cite this article as: Sokkary $\mathrm{HH}$, The efficacy of ultrasonographic morphological index using Depriest score in ovarian cancer prediction. Int J Reprod Contracept Obstet Gynecol 2016;5:4200-5. 